\title{
Da história oral ao filme de pesquisa: o audiovisual como ferramenta do historiador
}

\author{
From oral history to the research film: the audiovisual \\ as a tool of the historian
}

\section{Hebe Mattos}

Professora, Departamento de História/Universidade Federal Fluminense (UFF).

Campus Gragoatá - Bloco O - SI. 201 24210-350 - Niterói - RJ - Brasil

hebe.mattos@gmail.com

\section{Martha Abreu}

Professora, Departamento de História/UFF.

Campus Gragoatá - Bloco O - SI. 201 24210-350 - Niterói - RJ - Brasil

marthabreu@terra.com.br

\section{Isabel Castro}

Doutoranda, Programa de PósGraduação em Comunicação e Cultura/Universidade Federal do Rio de Janeiro; Sorbonne Nouvelle - Paris 3.

Av. Pasteur, 250/fundos

22290-240 - Rio de Janeiro - RJ

- Brasil

mattos.isa@gmail.com
MATTOS, Hebe; ABREU, Martha; CASTRO, Isabel. Da história oral ao filme de pesquisa: o audiovisual como ferramenta do historiador. História, Ciências, Saúde - Manguinhos, Rio de Janeiro, v.24, n.4, out.-dez. 2017, p.1147-1160.

\section{Resumo}

Ensaio analítico do processo de produção de imagens, formação de arquivo audiovisual, análise das fontes e criação da narrativa fílmica dos quatro filmes historiográficos que formam a caixa de DVDs Passados presentes, do Laboratório de História Oral e Imagem da Universidade Federal Fluminense (Labhoi/UFF). A partir de trechos do arquivo audiovisual do Labhoi e dos filmes realizados, o artigo analisa: como o problema de pesquisa (a memória da escravidão e o legado da canção escrava no agrofluminense) nos levou à produção de imagens em situação de pesquisa; o deslocamento analítico em relação ao documentário cinematográfico e ao filme etnográfico; as especificidades de revisitar o acervo audiovisual constituído a partir da formulação de novos problemas de pesquisa.

Palavras-chave: imagem; escravidão; história oral; memória; filme de pesquisa.

\section{Abstract \\ An analytical essay of the process of image production, audiovisual archive formation, analysis of sources, and creation of the filmic narrative of the four historiographic films that form the DVD set Passados presentes (Present pasts) from the Oral History and Image Laboratory of Universidade Federal Fluminense (Labhoi/UFF). From excerpts from the audiovisual archive of Labhoi and the films made, the article analyzes: how the problem of research (the memory of slavery, and the legacy of the slave song in the agrofluminense region) led us to the production of images in a research situation; the analytical shift in relation to the cinematographic documentary and the ethnographic film; the specificities of revisiting the audiovisual collection constituted by the formulation of new research problems.}

Keywords: image; slavery; oral history; memory; research film. 


\section{Do som à imagem: do texto à imagem}

A imagem de capa do livro Memórias do cativeiro (Mattos, Lugão Rios, 2005) é a foto de um álbum de família da década de 1940, construído a partir de fotografias 3x4 tiradas para as carteiras de trabalho dos fotografados. Cornélio Cansino, autor do álbum, foi um dos principais depoentes de Ana Lugão Rios durante a pesquisa de história oral desenvolvida, no início dos anos 1990, para a sua tese de doutorado, com camponeses negros do vale do Paraíba Fluminense descendentes da última geração de escravizados na região (Lugão Rios, 2001).

As entrevistas genealógicas desenvolvidas por Ana para abordar a memória sobre antepassados escravos junto a camponeses negros do vale do Paraíba estiveram, desde o início, comprometidas com a formação do acervo "Memórias do Cativeiro" no Laboratório de História Oral e Imagem da Universidade Federal Fluminense (Lebhoi/UFF), em associação com Hebe Mattos (1998) e Robson Martins. Na verdade, constituíram a base metodológica para sua fundação. Nelas, as imagens não estavam necessariamente previstas, mas as fotos de família, raras, e muito valorizadas quando existentes, surgiram com um lugar de destaque na memória dos entrevistados. Era o caso principalmente das fotos de casamento ou do casal, transformadas em quadro e penduradas na parede, que permitem perceber o alcance social da fotografia na primeira metade do século XX, símbolo de status e respeitabilidade para os entrevistados. ${ }^{1}$

Entre essas fotos, o autointitulado "álbum de família" de seu Cornélio Cansino se destacava pelo potencial de agregação de sentidos que trazia. Ele simbolizava a importância da família na construção da identidade do entrevistado, ao mesmo tempo que representava sua leitura da era Vargas como o tempo de uma "segunda abolição", diretamente associada à carteira de trabalho como documento gerador de cidadania. O tema foi abordado em artigo de Hebe Mattos e Ângela de Castro Gomes, no número um da revista da Associação Brasileira de História Oral (Castro Gomes, Mattos, 1998). Mas o álbum revelava também, ao pesquisador atento, como a obrigatoriedade da fotografia no documento público abriu novas possibilidades de acesso à imagem individual e, portanto, à construção de autoimagem por parte das classes trabalhadoras.

O papel da fotografia para documentos oficiais e da foto de casal/casamento como signos de pertencimento e cidadania na primeira metade do século XX é um tema que fica aqui sugerido, do ponto de vista analítico, para pesquisas mais aprofundadas. É, porém, a força expressiva dessas imagens e sua importância do ponto de vista narrativo que buscamos mais especificamente problematizar no presente artigo.

O livro Memórias do cativeiro representou uma importante inovação em termos da estruturação do texto historiográfico na pesquisa em história oral do Labhoi/UFF. A escritura polifônica do livro, com a edição das falas dos entrevistados a partir de coincidências narrativas, e o discurso analítico em duas vozes das autoras (com Hebe analisando a história da memória e Ana a experiência do pós-emancipação) procurou trazer a dimensão do lugar de fala para dentro da análise que emergia como resultado da pesquisa. Apesar disso, o livro publicado incorporava as imagens produzidas por Ana Lugão apenas como ilustrações. As duas autoras sabiam, porém, que elas poderiam "falar" muito mais. 
O desejo de construir uma narrativa em imagem e sons a partir do roteiro do livro marca o encontro das três autoras desse texto para a aventura de produzir, pela primeira vez, uma escrita audiovisual. Ana Lugão acompanhou toda a experiência de criação desse primeiro filme, ainda que como consultora. Nossa inspiração inicial era a primeira experiência do Labhoi com a escrita audiovisual em história oral, desenvolvida por Ana Maria Mauad, para o filme O incêndio do Gran Circus Norte-Americano (O incêndio..., 2003). A proposta inicial do documentário Memórias do cativeiro (Memórias..., 2005) era dar acesso ao público à voz dos entrevistados, produzindo interpretações específicas e novos sentidos a partir delas, em função da intertextualidade dos trechos de fala escolhidos, com cartelas interpretativas, música e imagens de época. Isabel Castro e Guilherme Fernandez, então jovens profissionais de audiovisual que compunham a equipe, sugeriram também filmar novas entrevistas com os depoentes do Quilombo São José da Serra e sua então já famosa festa do 13 de maio, de forma a fazer deles os narradores principais do futuro filme. Como bem sabem os que conhecem a obra, o livro Memórias do cativeiro termina com um capítulo sobre a história do Quilombo São José e seu grupo de jongo, que haviam ganhado visibilidade nacional desde a primeira entrevista de Ana Lugão com dona Zeferina, matriarca da comunidade, em 1994. Martha Abreu, inicialmente agregada às discussões como consultora, sugeriu mais, incitou a equipe a registrar em vídeo a cultura material da velha sociedade do café ainda presente no vale do Paraíba, especialmente as estruturas das antigas fazendas e senzalas, para dialogar com as coincidências narrativas recolhidas em áudio no arquivo do Labhoi. Assim, surgia a decisão de produzir imagens em movimento para compor a narrativa do filme, ainda que como imagem complementar à pesquisa original.

\section{Novas fronteiras da pesquisa histórica: 0 audiovisual}

A narrativa de Memórias do cativeiro foi diretamente baseada na primeira parte do livro homônimo, mantendo sua estrutura em cinco blocos de depoimentos, ligados por sua temática: "A África no Brasil", "O tempo do cativeiro", "Laços de família", "Visões da liberdade" e "Diálogo dos tempos". ${ }^{2}$ Algumas cartelas explicativas, também editadas a partir do livro, entrecortavam os depoimentos, representando o discurso - ou observações - do historiador. Foi, portanto, a partir do desafio de adaptar uma pesquisa prévia a um filme, que fomos descobrindo na prática como o audiovisual poderia contribuir para as questões da pesquisa histórica.

Em relação ao texto, uma primeira diferença evidente trazida pelo meio diz respeito às falas, que no filme vêm acompanhadas de uma voz, além de um corpo, um rosto e uma gesticulação, que acrescentam dimensões ao que é dito. Os depoimentos sobre separações familiares e castigos, por exemplo, ganham em Memórias peso e força pelo acesso ao áudio da narrativa dos entrevistados. Os personagens que integram as diversas histórias contadas também ganham interpretações particulares por meio da entonação da fala, como por exemplo quando seu Cornélio imita a voz de seu pai ao contar uma de suas histórias, no bloco "Laços de família". Principalmente, aspectos da oralidade, como vocabulários, expressões e formas de contar, são colocados em evidência. Assim, as coincidências narrativas culturalmente significativas, ou etnotextos, na acepção proposta por Philippe Joutard (1980), principal matéria-prima desse 
filme e dos que o seguiram, muitas vezes vão além do conteúdo do que é dito e aparecem justamente na forma de interpretar certos personagens em diferentes histórias, no emprego de determinadas palavras, expressões ou gestos, nos cantos (por vezes uma mesma melodia pode vir acompanhada de letras variadas), ou nas danças - etnotextos que muitas vezes se materializavam em performances.

A escrita audiovisual nos trazia, assim, a possibilidade de incorporar, aos depoimentos orais, outras formas expressivas, como performances de jongo, com seus conteúdos de memória corporal, e paisagens de cultura material, sobretudo de fazendas históricas da região do antigo vale do Paraíba.

De fato, a performance é um dos mais visitados temas da antropologia visual e do filme etnográfico. Desde então, nosso olhar tem dialogado intensamente com essa área de pesquisa, sobretudo desde a criação do Festival Internacional do Filme de Pesquisa, em 2008. ${ }^{3}$ Muito aprendemos com os antropólogos sobre a dimensão de negociação entre conhecimento acadêmico e experiência social dos grupos pesquisados para construção da imagem a ser veiculada nos filmes de pesquisa. Nosso segundo filme, de 2007, Jongos, calangos e folias: música negra, memória e poesia (Jongos..., 2007), recebeu menção honrosa do Prêmio Manoel Diegues Junior na $13^{\text {a }}$ Mostra Internacional do Filme Etnográfico, em 2008. Refletindo nossa origem na história oral, o prêmio nos foi atribuído "pelo uso da oralidade como instrumento de afirmação entre diferentes práticas culturais". ${ }^{4}$ Desde então, o Labhoi tornou-se lugar de referência e troca sobre a experiência etnográfica no campo da antropologia visual sobre a memória da escravidão no Brasil. Apesar da intensa troca, a visionagem comparativa dos filmes sobre o tema no site do Festival do Filme de Pesquisa permite entrever o sotaque historiográfico dos vídeos do Labhoi. Nosso interesse pela memória vai além da presença do passado no presente etnográfico da filmagem, buscando produzir um diálogo entre conhecimento histórico e memória coletiva para criar, no roteiro dos filmes, um novo conhecimento historiográfico sobre a memória da escravidão e o pós-abolição.

Um dos maiores desafios para transformar a pesquisa do livro Memórias do cativeiro em filme se deu porque parte das entrevistas utilizadas, realizadas por uma pesquisa da USP de 1987-1988, só existia como texto - transcrição dos depoimentos orais -, pois as fitas gravadas propriamente ditas haviam sido perdidas (Memória..., 1988). Como solução, decidimos pedir a alguns dos moradores do Quilombo de São José da Serra para as lerem, diante da nossa câmera. Eles concordaram e participaram de forma entusiasmada das filmagens. Ao fazê-lo, a tese de conclusão do livro - sobre a construção da identidade quilombola na comunidade negra da antiga Fazenda de São José da Serra a partir de uma reapropriação política da memória do cativeiro - foi concretamente encenada, para o filme, pelos quilombolas. O diálogo entre história e memória se efetiva, também, nas cartelas narrativas com a voz do historiador, no roteiro de Memórias do cativeiro.

Sobre a questão da cultura material, é interessante notar que a filmagem de lugares do passado no presente - isto é, o registro visual de indícios materiais de um espaço - é bastante comum no cinema em sentido amplo, por sua força como elemento sobrevivente ao tempo, portador de memória e afeto. Em seu pequeno livro L'attrait de la ruine, o pesquisador André Habib (2011) investiga a sedução do cinema por vestígios materiais do passado, ao analisar fragmentos de certos filmes de ficção. O autor ressalta que o segredo dessa atração não está 
na ruína em si, mas na representação desta, na figuração da presença de uma ausência, em busca de uma experiência sensível de tempo. Assim, alguns filmes, ao permitirem que os espectadores se deparem "com um tempo passado através de uma consciência da história que os separa deste, no presente" (p.8), são capazes de colocar em evidência o próprio tempo que passa, além de evocar a imaginação de outro tempo inalcançável. Esse recurso de filmar no presente o local de experiências passadas é especialmente utilizado no cinema documentário contemporâneo interessado pela memória, seja ela pessoal ou histórica. Os lugares e paisagens, vestígios de experiências evocadas, trazem em si uma força afetiva e podem servir para desencadear narrativas orais sobre o passado. Quando voltamos a câmera aos lugares do passado no presente, a intenção historiográfica bebe na experiência do filme documentário, ou do cinema em sentido amplo, para refletir sobre a memória como experiência mutante e portadora de história.

Para o Memórias do cativeiro, foi filmada, por exemplo, a sala de castigos da fazenda Santa Clara, que ainda continha muitos instrumentos de tortura de época, trazendo-nos com muita força vestígios materiais da dor do passado (para nós e para os espectadores do filme). Também tínhamos a informação de que as senzalas dessa fazenda possuíam janelas falsas pintadas nas suas paredes exteriores. Ao conversar com seu Manuel Seabra do quilombo de São José, então com oitenta e muitos anos, para nossa surpresa ele mencionou essas falsas janelas, que ele lembrava ter visto ainda criança, apesar de nunca mais ter ido a essa fazenda. O impacto de vê-las e filmá-las ainda lá, camuflando seu espaço claustrofóbico interior, hoje vazio, resulta em uma imagem enriquecida de camadas de memórias que evocam a senzala do passado.

No caso da história, além disso, a cultura material pode servir para trazer informações concretas de pesquisa e dialogar com a bibliografia existente sobre diversos temas. Por meio das casas de São José, pudemos observar suas estruturas de "pau a pique", entender mais sobre as dinâmicas das festas, e ver, por exemplo, o teto de folhas de bananeira preparado para as noites de baile, sob o qual, até um passado recente, se escondiam pedaços de pau que poderiam ser sacados no caso da eclosão de uma briga (elemento trabalhado no filme Jogo do pau, que será analisado mais adiante). O recurso à força expressiva da ruína seria retomado com força na linguagem visual do filme Passados presentes (Passados..., 2011). Definia-se ali todo um repertório de possibilidades que nortearia a construção visual dos filmes posteriores.

Por último, vale ressaltar que o processo de filmagens, ainda que curto, acabou se configurando também como um método de pesquisa, que incorporava a imprevisibilidade na sua própria produção. Ainda que pensadas como complementares às entrevistas do livro, as filmagens realizadas para Memórias do cativeiro produziram novos conhecimentos. Foi a primeira filmagem da festa do 13 de maio em São José da Serra, realizada em 2005, que nos fez descobrir a força e a atualidade do jongo, em desacordo com tudo que até bem recentemente a maioria dos pesquisadores, fossem folcloristas, antropólogos ou historiadores, havia profetizado (Abreu, Mattos, 2007). As filmagens nos levaram a buscar entender a história social das dezenas de comunidades jongueiras, das mais diferentes partes do estado do Rio de Janeiro, reunidas, em 2005, na festa do 13 de maio do Quilombo São José. Martha Abreu, em especial, historiadora da música negra, questionava-se sobre a surpreendente resistência da canção escrava, expressa na expressividade do jongo e sobre os significados do baile do calango, que acontecia paralelamente, dividindo a festa com a roda de jongo ao redor 
da grande fogueira. Foi com base nessas questões que nascia um novo projeto de pesquisa, "Jongos, calangos e folias: música negra, memória e poesia", onde a metodologia de história oral era redimensionada, colocando a filmadora no lugar do velho gravador. A criação de um arquivo audiovisual de entrevistas genealógicas com mestres jongueiros era nosso primeiro e principal objetivo de pesquisa, ${ }^{5}$ porém, desde a formatação do projeto para ser apresentado ao Edital Petrobras Cultural de Patrimônio Imaterial de 2005, prevíamos também a elaboração de um filme historiográfico, refletindo sobre os principais resultados da pesquisa realizada.

\section{O filme historiográfico como resultado de pesquisa: Jongos, calangos e folias}

Muito diferente de Memórias, portanto, a pesquisa de Jongos foi desde o início realizada por meio da produção de imagens filmadas. A ideia não era mais a de adaptar uma pesquisa prévia a um filme, mas utilizar o audiovisual como meio de uma nova pesquisa com múltiplos fins.

Por meio da história oral, começamos a registrar a memória e a trajetória dos grupos e de suas atividades festivas e musicais. Para isso, realizamos entrevistas com equipamentos de filmagem e organizamos genealogias, reconstituídas por meio dos depoimentos orais. Quando possível, levantamos registros de nascimento, óbitos e inventários das antigas fazendas. O roteiro de pesquisa envolveu entrevistas com os mais antigos e com os principais jongueiros, foliões de reis ou calangueiros das comunidades visitadas, que incluíam diversas regiões do Rio de Janeiro, como Angra dos Reis, Búzios, Valença, Barra do Piraí, Duas Barras e Baixada Fluminense. Tudo começava com as perguntas sobre a família, região de origem e levantamento dos antepassados e parentes. Em seguida sobre jongos, calangos e folias. Como aprenderam? Quando faziam? O que significavam para o grupo? Tentávamos articular história social com história cultural e política. Genealogias familiares com patrimônio cultural. Realizamos também filmagens das principais festas e manifestações musicais.

No contexto de um projeto de história oral previamente constituído, como no caso da pesquisa que resultou no filme Jongos, calangos e folias, a imprevisibilidade foi ainda mais fortemente incorporada à metodologia. As surpresas no curso das filmagens passam a determinar muitas vezes o próprio roteiro do que será filmado para ser depositado no acervo audiovisual em construção. Cada entrevista, festa e situação frequentemente se desdobrando em possíveis outros lugares, pessoas, festas e manifestações culturais a serem registradas. Além de possibilitar o aumento crescente dessa rede de informações, novas questões de pesquisa foram constantemente incorporadas pela pesquisa de campo.

Ao todo, foram produzidas mais de 180 horas de filmagens, hoje disponíveis no "Acervo Petrobras Cultural Memória e Música Negra". A criação desse arquivo era, em si, o principal objetivo do projeto. Depois de cada filmagem, todas as fitas gravadas eram decupadas. Ou seja, era feita uma discriminação do material contido na fita, incluindo, por exemplo, o local da gravação, nome do entrevistado e um resumo do conteúdo de cada fala com sua respectiva referência de tempo na fita (timecode) para o processo de arquivamento.

Essas decupagens estão abertas a pesquisa, disponíveis no arquivo on-line do Labhoi, e foram uma base importante para a etapa de edição do documentário concluído em 2007. Em meio a tanto material, as decupagens organizadas permitiam mais facilmente fazer aproximações entre os personagens, os assuntos das falas e as manifestações musicais, para 
então se pensar a estrutura do filme. Como escreve o montador e diretor de cinema Eduardo Escorel (2006, p.20-23), "montar ou editar consiste em escolher e justapor. Apenas isso. É uma operação simples, comum a toda linguagem. ... Quem se exprime por meio da linguagem cinematográfica seleciona e combina imagens e sons". De uma forma próxima ao que fazemos para construir um artigo ou um livro, portanto, começamos a escolher os trechos das entrevistas que seriam citados de uma forma mais longa no filme. Vale ressaltar que, no caso de um filme, elementos técnicos como a qualidade do som e da imagem também foram considerados nessa seleção. Selecionados algumas falas importantes, a editora Isabel Castro começou a fazer propostas de articulação entre os depoimentos, que, semanalmente, eram discutidas por nós três, frequentemente acompanhadas de outros pesquisadores, estudantes e consultores que fizeram parte do projeto. Ao longo da montagem, a estrutura do filme foi sendo construída coletivamente, resultando no documentário, que consideramos um artigo acadêmico em formato audiovisual.

A analogia entre filme e texto é corrente no pensamento sobre o cinema. Sem entrar na vasta discussão teórica do cinema como linguagem ou nas implicações dessa analogia nas metodologias de análise fílmica, é interessante para nós evocá-la aqui, por ter sido ela muito presente no processo. Analogamente à nossa produção de textos escritos (a qual Hebe e Martha estavam acostumadas), com o filme estávamos construindo um discurso, organizando uma narrativa, mas com base em materiais de expressão - citando o termo utilizado por Christian Metz (1971) - próprios ao audiovisual. Portanto, mesmo com outro tipo de material, de resultado, de recepção e de controle sobre as teses formuladas, sentíamos que estávamos construindo uma outra forma de texto histórico. As pistas, ideias e hipóteses historiográficas apresentadas em Jongos, calangos e folias são formuladas por meio do filme e não refletem um pensamento organizado pelas pesquisadoras em textos anteriores. É um artigo inédito, audiovisual, que, por ter outros alcances e possibilidades em relação ao texto escrito, não esgota a possibilidade, como foi o caso, de outros textos nascerem a partir dele.

O roteiro desse filme-artigo começa com uma introdução que reúne os entrevistados das diversas regiões, mostrando o quanto as três manifestações culturais em questão: o jongo, o calango e as folias de reis, entrecortam os diversos discursos - e como elas demonstram um parentesco evidente entre si, presente na dimensão do improviso e do desafio verbal na forma de versos, comum às três de diferentes formas.

Em seguida, o corpo do roteiro se constrói em grande parte inspirado em um dos principais achados da pesquisa, a ideia de que o mapa dos grupos jongueiros do século XXI conta a história da última geração de africanos chegada como trabalhadores escravizados nas antigas áreas cafeeiras do Sudeste e seus descendentes. O filme começa, assim, com as comunidades do litoral do estado, local de desembarque dos últimos africanos chegados como escravos no Brasil (Quilombo do Bracuí, em Angra dos Reis, e Quilombo da Rasa, em Búzios). Em seguida, sobe a serra do Mar rumo ao vale do Paraíba, local das antigas plantations cafeeiras, para onde se dirigiu grande parte dos recém-chegados (comunidades de Barra do Piraí, Quilombo São José da Serra e Duas Barras). Por fim, desce a serra até a Baixada Fluminense, acompanhando as migrações de ex-escravos e seus descendentes no pós-abolição, em diferentes momentos do século XX. Um mapa com as diferentes regiões pesquisadas e informações sobre os entrevistados está disponibilizado como anexo no site e no DVD do filme. 
A narrativa mostra como as três manifestações, à primeira vista culturalmente distintas, entrelaçam-se e interinfluenciam quando apropriadas por atores sociais específicos. Essa reflexão é acentuada pelas passagens, na edição do filme, entre cada uma das manifestações, que se fazem evidenciando diálogos, empréstimos e apropriações. Podemos exemplificar esse dispositivo com a passagem do jongo ao calango, compartilhando um mesmo verso ou com a passagem do calango à folia de reis, praticado pelos mesmos personagens. Na conclusão do filme, um terceiro eixo de construção da narrativa fílmica se torna explícito, o sentido político da construção da identidade negra pesquisada.

Enfatizando o diálogo entre história e memória, os comentários dos historiadores também estão presentes no filme. Não por cartelas informativas, como no caso de Memórias, mas, principalmente, a partir de uma conversa entre historiadores, ${ }^{6}$ realizada na praia do Bracuí durante uma das viagens da pesquisa e diversas entrevistas das diretoras/historiadoras com especialistas nas questões abordadas pelo filme.

Nesse debate, diversos temas levantados a partir dos resultados da pesquisa de história oral foram discutidos. Dessa forma, o discurso do historiador é incluído no filme também em processo, por meio de um levantamento de questões e hipóteses que é simultâneo às descobertas da pesquisa; e não como um discurso fechado relacionado a imagens e depoimentos que neste se enquadram ou o ilustram.

Em Jongos, calangos e folias o discurso dos historiadores presente no filme, de certa forma, segue a avalanche de informações surgidas no decorrer do processo. O discurso historiográfico do filme, como texto audiovisual, é, portanto, mais amplo do que a conversa entre os historiadores, que se configura como mais um elemento de informação e questionamento.

\section{Escrevendo a história em filme: Passados presentes}

O arquivo audiovisual Petrobras Cultural Memória e Música Negra, constituído ao longo de 2007, foi disponibilizado para pesquisa no mesmo ano do lançamento de Jongos, calangos e folias, então com mais de 180 horas de entrevistas e registro de performances arquivados e indexados por assunto. Naquele momento, tínhamos clara consciência de que alguns achados da pesquisa não tinham sido aprofundados no nosso primeiro documentário. Em termos de práticas culturais, tínhamos muito a dizer sobre o jogo do pau, ou capoeira do cacete. Tínhamos também descoberto uma expressiva tradição oral relativa à última fase (já formalmente ilegal) do tráfico negreiro no Rio de Janeiro. Era nosso intento dar continuidade à construção de análises audiovisuais sobre esses temas, a partir do nosso próprio arquivo.

A realização dos terceiro e quarto filmes acabou gerando uma tetralogia que compõe a caixa de DVDs Passados presentes (Mattos, Abreu, 2012), retomando filmagens que compõem o Acervo Petrobras Cultural Memória e Música Negra para construir outras narrativas com esses temas específicos. O primeiro filme, Versos e cacetes: o jogo do pau na cultura afro-fluminense (Versos..., 2009), dirigido por Matthias Rörig Assunção e Hebe Mattos, documenta o jogo do pau e sua inserção na cultura afro-fluminense no vale do Paraíba. O segundo, Passados presentes: memória negra no Sul Fluminense, coloca em destaque a vigorosa tradição oral de descendentes de escravizados nos antigos domínios da família Souza Breves na região sul 
do estado do Rio de Janeiro (Bracuí e Pinheiral), tendo como foco principal a questão do tráfico ilegal de africanos.

Matthias Assunção, historiador da Universidade de Essex, no Reino Unido, aproximou-se ainda em 2007 do projeto Jongos, calangos e folias, tornando-se um importante colaborador. Especialista na história da capoeira (Assunção, 2002) e já interessado pelo jogo do pau - um parente da capoeira que foi bastante comum nas regiões rurais do sudeste brasileiro e que existe de diferentes formas em países africanos e da diáspora negra -, Matthias se questionava sobre a força de sua presença na região do vale do Paraíba. Ao longo das entrevistas, o jogo do pau revelou-se, assim como os jongos, os calangos e as folias, parte da memória de entrevistados de diferentes lugares, apesar de quase não ser mais praticado à época das entrevistas.

Somente dois anos depois, o projeto de fazer um documentário específico sobre o jogo do pau foi iniciado, a partir da visionagem do material produzido na pesquisa de 2007 . Foi a partir desse arquivo que novas entrevistas foram decididas e realizadas. Matthias Assunção selecionou ainda algumas imagens de arquivo das variantes do jogo do pau em diversos países, como Haiti, Venezuela e Portugal para a montagem final.

Versos e cacetes constrói e rememora o jogo do pau, partindo do contexto da prática no início do século XX e chegando aos diálogos atuais com a capoeira e as novas gerações. A filmagem da roda de pesquisadores apresentada no filme se assemelha à ideia já desenvolvida em Jongos da reunião de um grupo de especialistas que, no momento dos resultados da pesquisa, discutem interpretações, hipóteses e associações possíveis, diante da câmera, sem apresentar uma leitura fechada sobre os assuntos abordados. Nesse caso, eles discutem também o próprio material filmado, já montado, e o que ele traz.

Se o reencontro com uma parte do material de Versos e cacetes, dois anos depois, já propicia um distanciamento analítico em relação às entrevistas e situações filmadas, o caso de Passados presentes é ainda mais radical nesse sentido. O último documentário da tetralogia é realizado, sobretudo, a partir do material produzido em 2007. É, portanto, um novo direcionamento de olhar, quatro anos depois, para o mesmo material de base de Jongos, que permite outra seleção de imagens e sons e consequentemente a construção de um novo filme, explorando, em nova escala, a interação entre depoimentos orais e documentos históricos. O testamento de José Breves, que doou as terras da antiga fazenda do Bracuí aos antigos trabalhadores libertos, e a documentação histórica sobre a repressão ao desembarque ilegal de cativos pelo brigue Camargo, em 1852, dialogam com a tradição oral, reforçando ou contradizendo-se mutuamente.

Ao se constituir como acervo, podemos considerar que o material bruto do filme Jongos, Calangos e folias se tornou um arquivo aberto, podendo ser utilizado por outras pesquisas e construção de novos filmes, a partir de uma reaproximação com o material, com uma nova intencionalidade. Foi o caso de Passados presentes e pode ser o caso de futuros filmes de outros autores. Como escreve a historiadora Sylvie Lindeperg (citada em Comolli, 2008, p.30): "Em função do contexto histórico, memorial, mas também da nova atenção que prestamos ao voltar à imagem, de repente direcionamos o olhar para alguma coisa que se camuflava na imagem e que ainda não tinha chegado até nós".

Ainda que todas as classificações de gêneros narrativos sejam fronteiras inventadas para serem rompidas, é possível dizer que a precedência do arquivo ao filme pode ser considerada 
como um sinal diacrítico do filme historiográfico, em relação ao filme etnográfico ou ao cinema documentário. $\mathrm{O}$ arquivo audiovisual, ainda que criado em paralelo ao roteiro do filme, também funciona como a referência documental imprescindível a um texto historiográfico, possibilitando uma escrita videográfica feita por historiadores. Esperamos, por isso, que as imagens que produzimos em situação de pesquisa possam continuar a responder a perguntas de novos pesquisadores e que possam ganhar novos sentidos em outros textos e filmes.

Ainda assim o filme historiográfico é filho da interdisciplinaridade. Sem a interlocução com o cinema e a antropologia, os quatro filmes não existiriam. Cinema é trabalho de equipe. O olhar de Guilherme Fernandez atrás das câmaras foi peça essencial do conjunto aqui analisado. Escrito a seis mãos pelas historiadoras e a montadora que participaram de todo o percurso, este artigo e as imagens que se seguem buscam consolidar o caminho que trilhamos juntos.

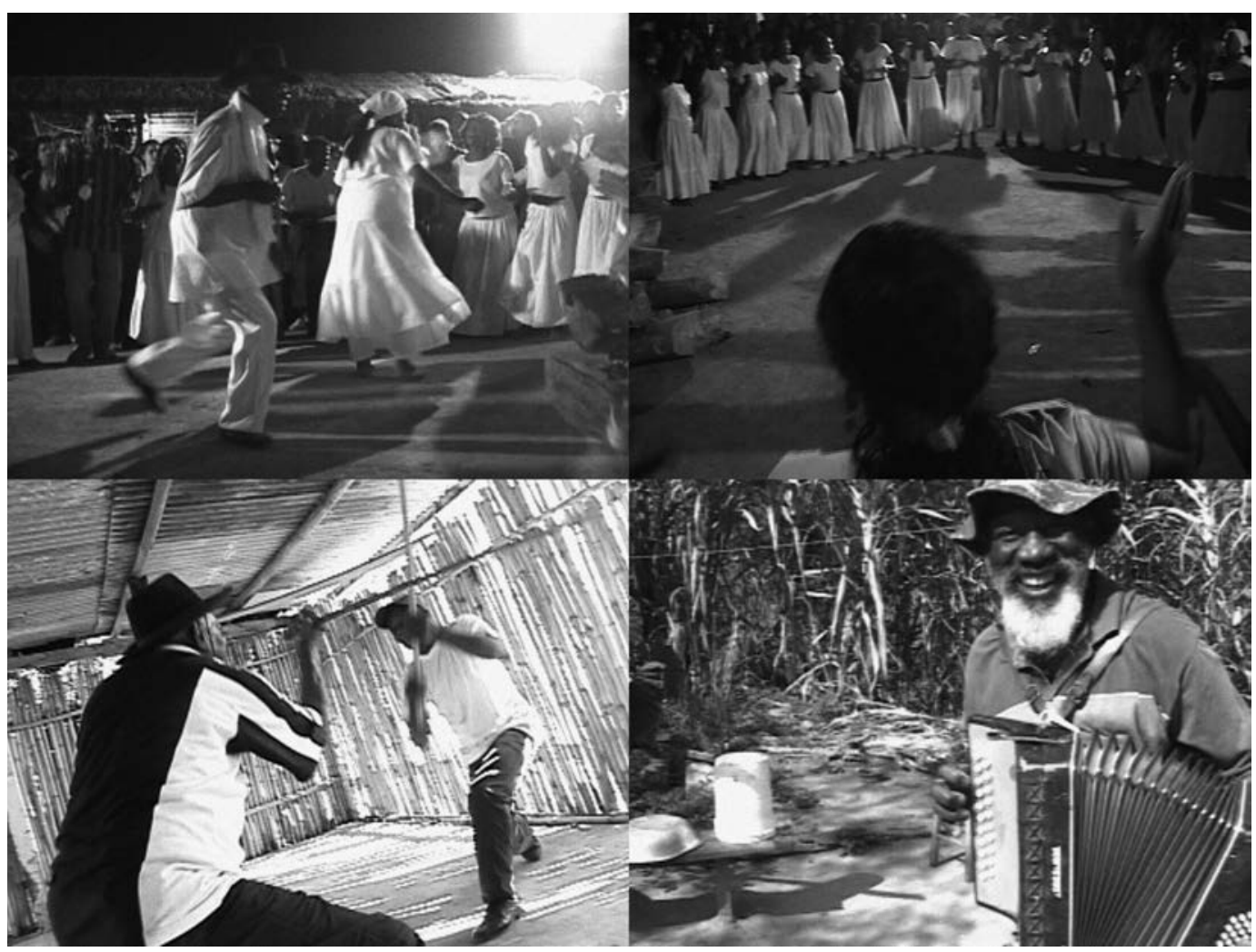

Figura 1: Performances de jongo, jogo do pau e calango. Acima, à direita e à esquerda: A roda de jongo do Quilombo São José da Serra, durante a festa do 13 de maio, em 2005. Os fotogramas integram os filmes Memórias do cativeiro (Memórias..., 2005) e Jongos, calangos e folias: música negra, memória e poesia (Jongos..., 2007). As filmagens do jongo, em 2005, realizadas para o filme Memórias do cativeiro, fizeram-nos descobrir a força e a atualidade do jongo no início do século XXI. Abaixo, à esquerda: seu Manuel Seabra e Jorge Fernandes praticam o jogo do pau no Quilombo São José da Serra. Muitos anos sem jogar, eles mostram e ensinam o jogo ao historiador Mathias Assunção e à equipe, nas filmagens de Versos e cacetes: o jogo do pau na cultura afro-fluminense (Versos..., 2009). Abaixo, à direita: seu Manuel do Calango toca uma melodia de calango em sua sanfona de oito baixos, em Pedro Carlos, distrito de Valença. Fotograma do filme Jongos, calangos e folias (2007). 


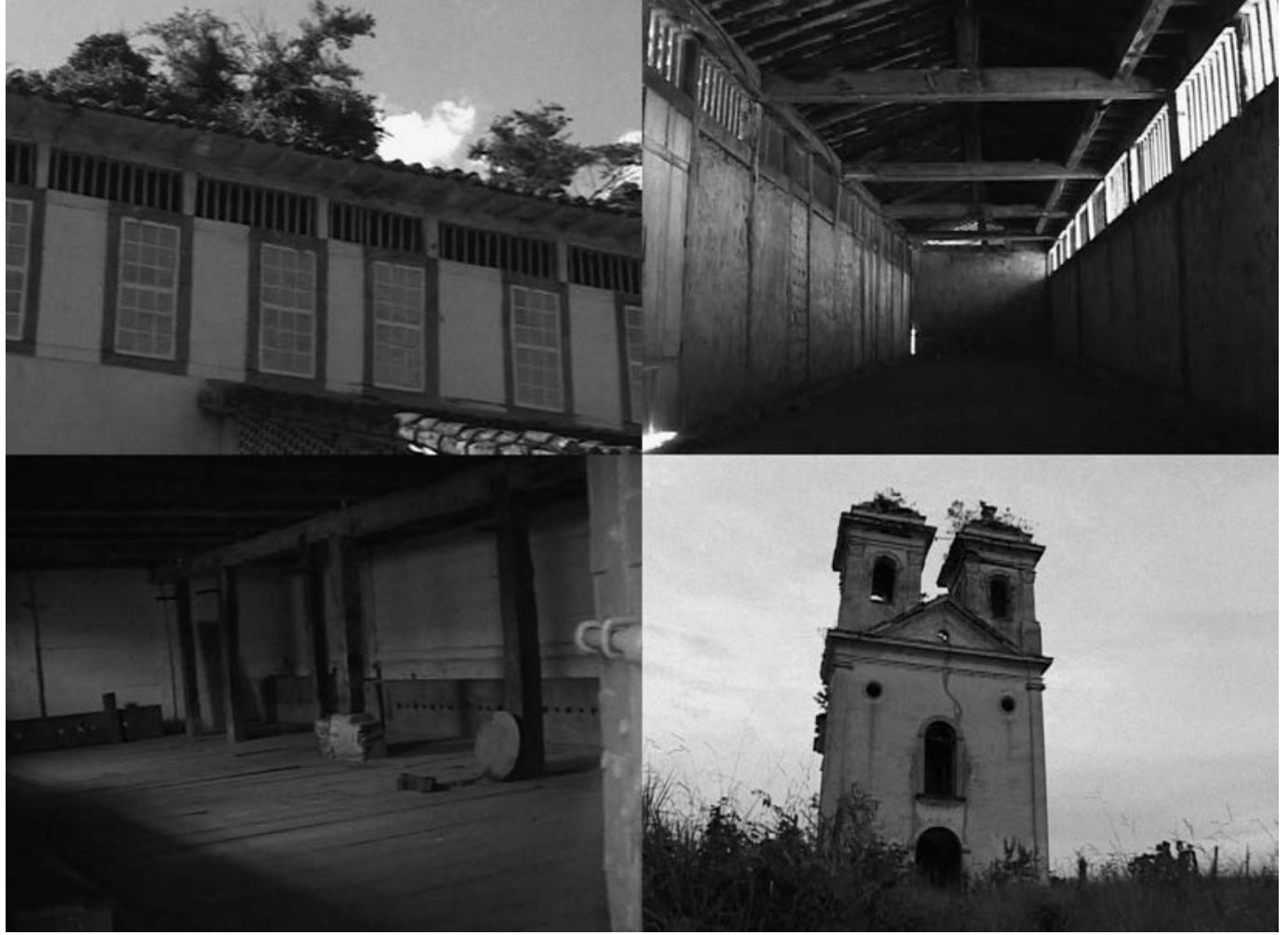

Figura 2: Vestígios da cultura material do vale do Paraíba. Acima, à esquerda: falsas janelas pintadas sobre parede externa da antiga senzala da Fazenda Santa Clara, em Santa Rita de Jacutinga, Minas Gerais. Acima, à direita: interior da antiga senzala da Fazenda Santa Clara, sem as divisórias originais. Abaixo, à esquerda: sala de castigos conservada na Fazenda Santa Clara. Fotogramas de Memórias do cativeiro (2005). Abaixo, à direita: Igreja da Fazenda da Grama, antiga igreja da fazenda sede de Joaquim de Souza Breves, onde foram enterrados os corpos da família. Fotograma de Passados presentes (2011).

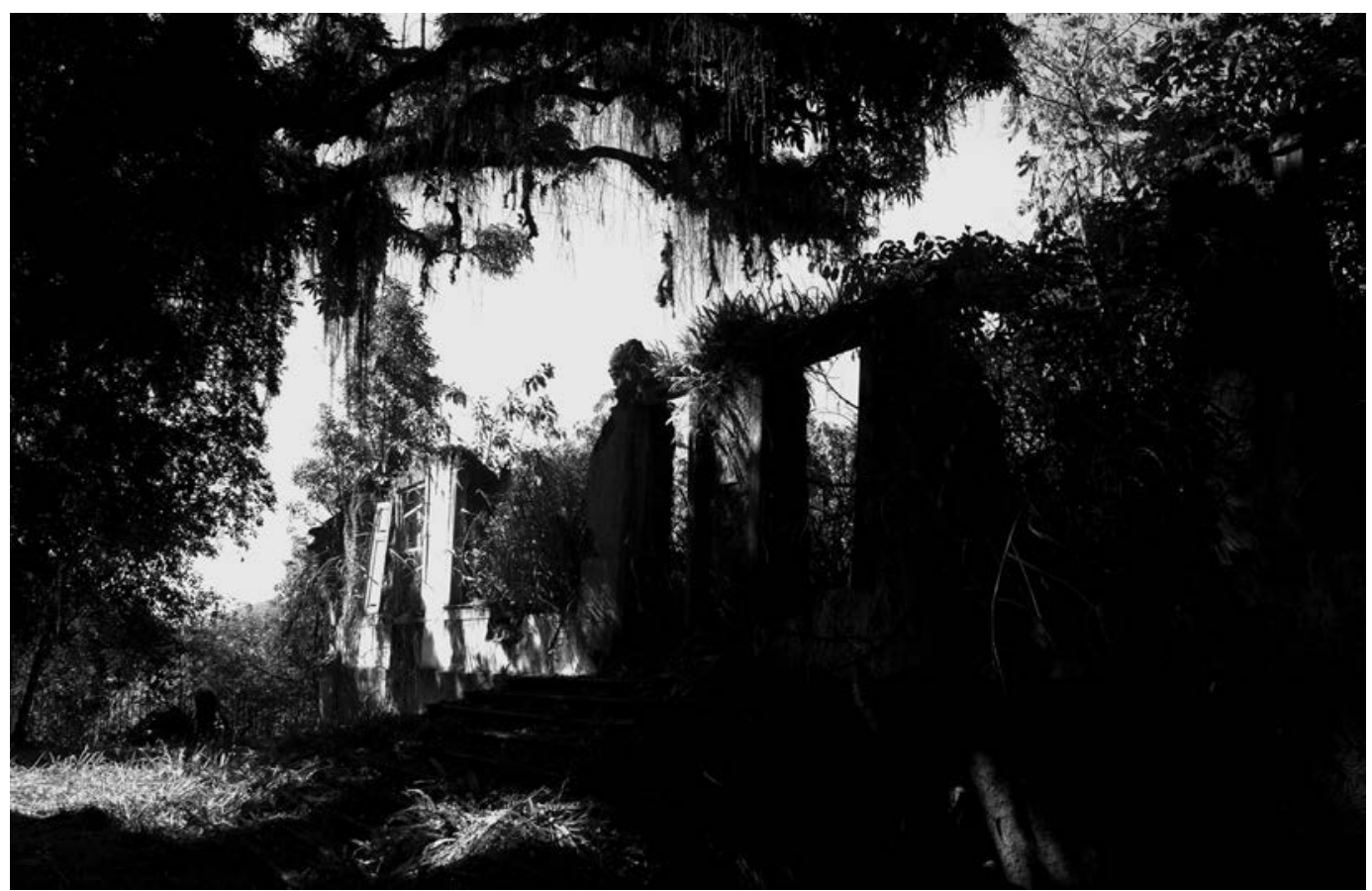

Figura 3: ruínas do casarão de Pinheiral, antiga sede da Fazenda do Pinheiro, de José de Souza Breves. Foto de Guilherme Hoffmann, 2015. Os restos do que foi o imponente casarão, de um dos mais ricos fazendeiros de café do Brasil na segunda metade do século XIX, representam a cultura material da velha sociedade do café ainda presente no vale do Paraíba. O local é palco de muitas histórias contadas sobre o passado, além de histórias atuais, de caráter místico, que são abordadas no filme Passados presentes (2011). 


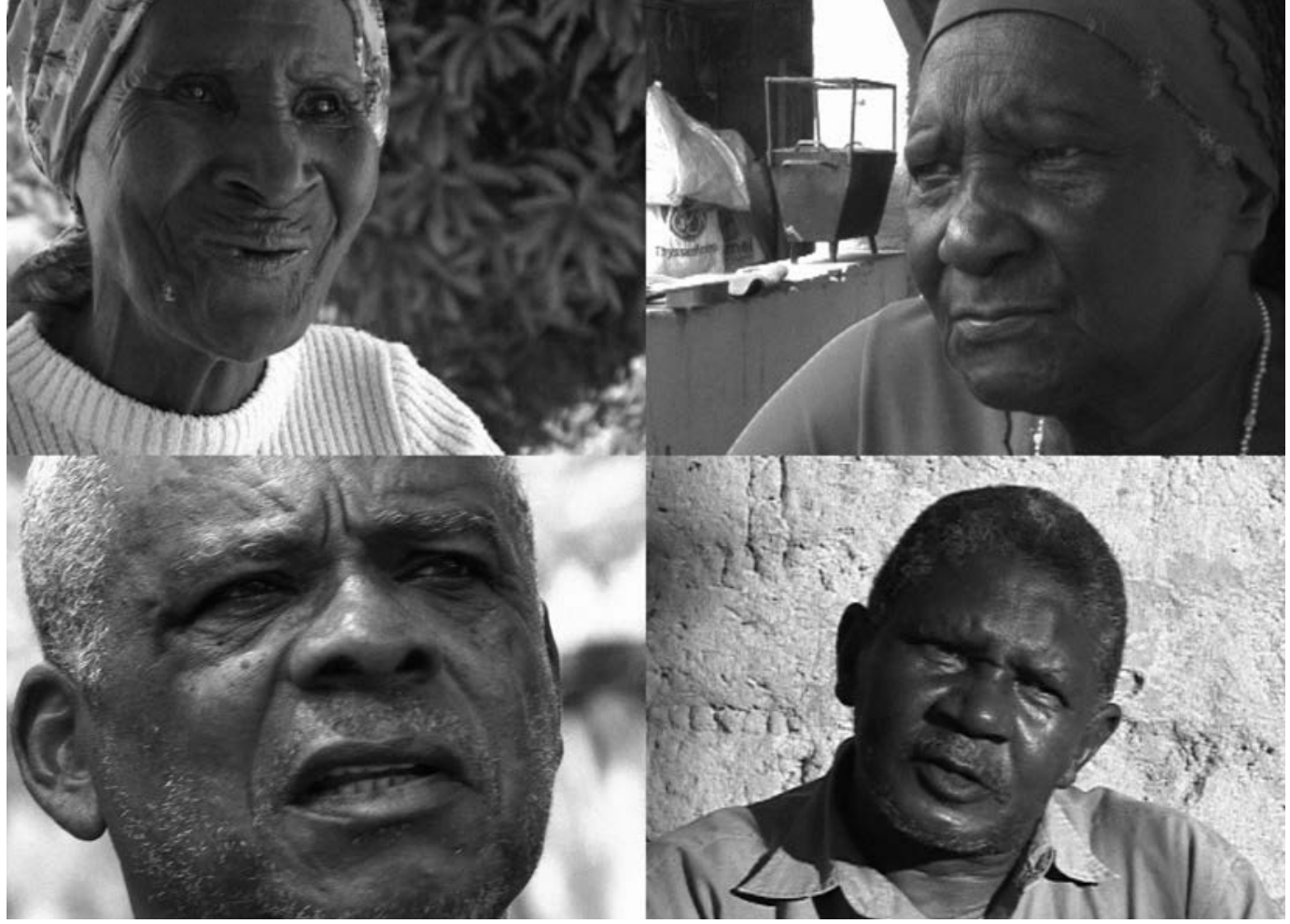

Figura 6: painel de depoentes dos quatro filmes. Acima, à esquerda: dona Cecília, Quilombo da Rasa, Búzios (Jongos, calangos e folias, 2007). Acima, à direita: tia Marina do Jongo, Barra do Piraí (Jongos, calangos e folias, 2007). Abaixo, à esquerda: seu Francisco Guilherme, Pinheiral (Passados presentes, 2011). Abaixo, à direita: seu João Batista, São José da Serra (Jongos, calangos e folias, 2007 e Versos e cacetes, 2009).

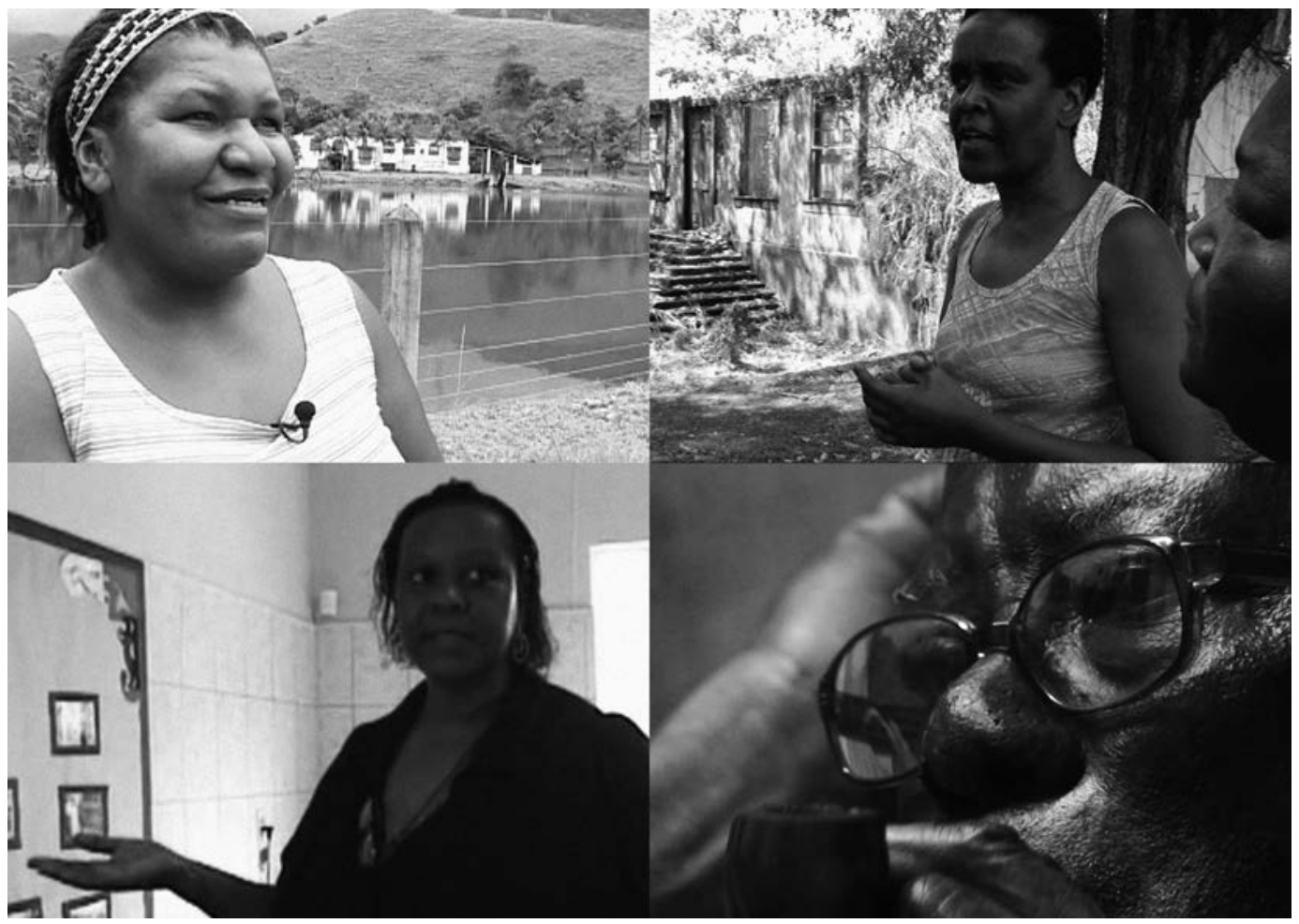

Figura 7: painel de depoentes dos quatro filmes. Acima, à esquerda: Marilda de Souza, Quilombo do Bracuí (Jongos, calangos e folias, 2007 e Passados presentes, 2011). Acima, à direita: Maria das Graças Silveira dos Santos e Adelaide, Pinheiral (Passados presentes, 2011). Abaixo, à esquerda: Maria da Fátima dos Santos na Casa do Jongo de Pinheiral (Passados presentes, 2011). Abaixo, à direita: seu Mário de Oliveira Pedro, de Pinheiral, fuma cachimbo em sua casa. Fotograma de Passados presentes (2011). 


\section{NOTAS}

${ }^{1}$ Fotos e pinturas de fotos de família em exposição nas casas de camponeses negros do Vale do Paraíba entrevistados por Ana Lugão Rios e Hebe Mattos podem ser vistas em: http://www.labhoi.uff.br/imagensdigitais/categorias/thumbs/236.

${ }^{2}$ Sobre o tema, ver o site Memórias do cativeiro: narrativas, em: http://www.labhoi.uff.br/narrativas/home.

${ }^{3}$ Sobre o Festival Internacional do Filme de Pesquisa Escravidão, Memória e Cidadania, ver o site do projeto, em: http://www.labhoi.uff.br/rff/index_pt.php.

${ }^{4}$ Sobre o prêmio, ver o site do Centro Nacional de Folclore e Cultura Popular, Prêmio Manoel Diegues Junior 2008, em: http://www.cnfcp.gov.br/interna.php?ID_Materia=150.

${ }^{5}$ Ver Memória e Música Negra: Acervo UFF Petrobras Cultural, em: http://www.labhoi.uff.br/jongos/acervo.

${ }^{6}$ Os historiadores que participam da conversa de Jongos, calangos e folias são Hebe Mattos, Martha Abreu, Robert Slenes e Matthias Assunção.

\section{REFERÊNCIAS}

ABREU, Martha; MATTOS, Hebe.

Jongo: registro de uma História. In: Lara, Silvia; Pacheco, Gustavo (Org.). Memória do jongo. Rio de Janeiro: Folha Seca. p.69-106. 2007.

ASSUNÇÃO, Matthias.

Capoeira: the history of an Afro-Brazilian martial art. Londres: Routledge. 2002.

CASTRO GOMES, Ângela de; MATTOS, Hebe. Sobre apropriações e circularidades: memória do cativeiro e política cultural na Era Vargas. História Oral, v.1, n.1, p.121-144. 1998.

COMOLLI, Jean-Louis.

Images d'archives: l'emboîtement des regards - entretien avec Sylvie Lindeperg. Images documentaires, n.63, p.11-39. 2008.

ESCOREL, Eduardo.

(Des)importância da montagem. Disponível em: http://www.portalbrasileirodecinema.com.br/ montagem/ensaios/04_02.php. Acesso em: 15 dez. 2015. 2006.

HABIB, André.

L'attrait de la ruine. Bruxelles: Éditions Yellow

Now. 2011.

JONGOS...

Jongos, calangos e folias: música negra, memória e poesia. Direção: Hebe Mattos e Martha Abreu. Brasil: Labhoi. 48min41s. 2007.

JOUTARD, Philippe.

Un projet regional de recherche sur les ethnotextes. Annales: Économies, Sociétés, Civilisations, ano 35, n.1, p.176-182. 1980.

LUGÃO RIOS, Ana M.

My mother was a slave, not me! Black peasantry and local politics in Southeast Brazil, c.1870-c.1940. Thesis (PhD) - University of Minnesotta, Minneapolis. 2001.
MATTOS, Hebe.

Os combates da memória: escravidão e liberdade nos arquivos orais de descendentes de escravos brasileiros. Revista Tempo, v.3, n.6, p.119-138. 1998.

MATTOS, Hebe; ABREU, Martha (Org.).

Passados presentes. (Caixa com 4 DVDs). Niterói: Eduff. 2012.

MATTOS, Hebe; LUGÃO RIOS, Ana M.

Memórias do cativeiro: família, trabalho e

cidadania no pós-abolição. Rio de Janeiro:

Civilização Brasileira. 2005.

MEMÓRIA...

Memória da escravidão em famílias negras de São Paulo; caixas 1 a 16. (Centro de Apoio à Pesquisa em História Sérgio Buarque de Holanda, São Paulo). 1988.

MEMÓRIAS...

Memórias do cativeiro: filme documentário, historiográfico e educativo. Direção: Guilherme Fernandez e Isabel Castro. Brasil: Labhoi. 42min 40s. 2005.

METZ, Christian.

Linguagem e cinema. São Paulo: Perspectiva. 1971.

O INCÊNDIO...

O incêndio do Gran Circus Norte-Americano.

Direção: Ana Mauad, Erica G. Daniel, Eduardo Mulder, Ana Flávia Cicchelli Pires e Tarsila Pimentel. Brasil: Labhoi. 20:50 min. Disponível em: http://www.labhoi.uff.br/node/1486. Acesso em: 24 nov. 2015. 2003.

PASSADOS...

Passados presentes: memória negra no sul fluminense. Direção: Hebe Mattos e Martha Abreu. Brasil: Labhoi. 43min. 2011.

VERSOS...

Versos e cacetes: o jogo do pau na cultura afrofluminense. Direção: Matthias Röhrig Assunção e Hebe Mattos. Brasil: Labhoi. 37min. 2009. 